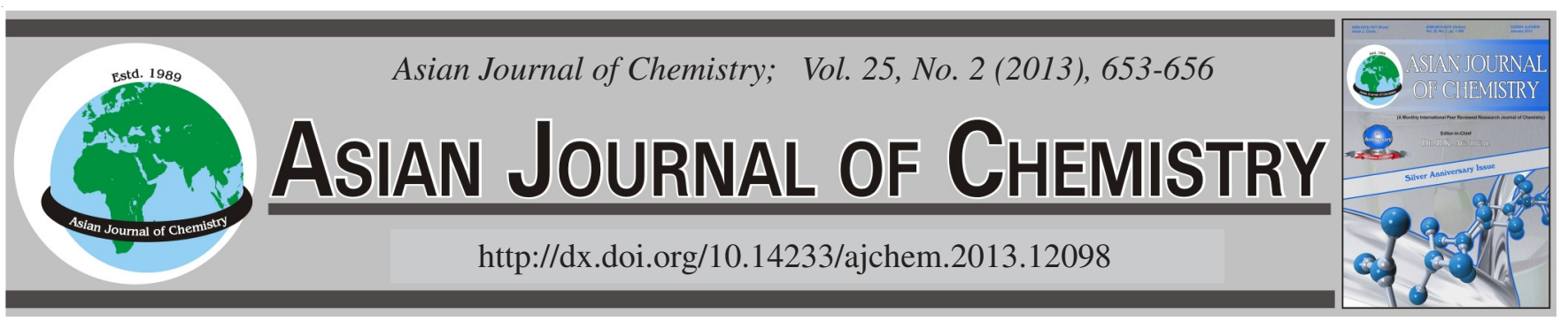

\title{
Prediction of Thermophysical Properties of Methane Based on Molecular Dynamics Simulations
}

\author{
ZHI ZHANG ${ }^{1,2}$, CHAO LiU ${ }^{2, *}$ and QI-BIN $\mathrm{LI}^{2}$
}

${ }^{1}$ State Key Laboratory of Oil and Gas Reservoir Geology and Exploitation, Southwest Petroleum University, Chengdu, P.R. China ${ }^{2}$ Key Laboratory of Low Grade Energy Utilization Technology and System of Ministry of Education, College of Power Engineering, Chongqing University, Chongqing, P.R. China

*Corresponding author: Fax: +8623 65112469; Tel: +86 23 65112469; E-mail: liuchao@cqu.edu.cn

\begin{abstract}
A method based on molecular dynamics simulation with empirical correlations is proposed to predict supercritical thermophysical properties (dynamic viscosity and thermal conductivity) of methane, which experiments are difficult to test on it. This approach to obtain density resembles experiments by molecular interactions which is differ from numerical analysis of equation of state. In our modeling, the average absolute deviation is $3.8,6.1$ and $5.2 \%$ of density, dynamic viscosity and thermal conductivity, respectively at $10 \mathrm{MPa}$ with temperature changing from 160-350 K. The density results matched perfect while simulated results of dynamic viscosity and thermal conductivity in average absolute deviation increased about $2 \%$ under the condition of simulated supercritical state. It is found that the deviations are mostly attributing to empirical correlations. This attractive issue will be discussed further in future.
\end{abstract}

Key Words: Methane, Molecular dynamics simulation, Thermophysical property, Dynamic viscosity, Thermal conductivity.

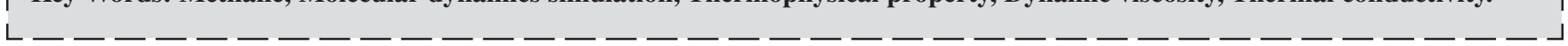

\section{INTRODUCTION}

Methane, the component of geologic fluid, is frequently encountered in many processes, such as mineral deposits, volcanic eruptions, magmatic activities, petroleum and natural gas industry. It's necessary to know its thermophysical properties. However, it's a tough work ${ }^{1}$ to experiment it for the wide range temperature and pressure underground. This is true of tapping natural gas. It experience series phase transition from supercriticality to normality while extracting along with the decline of temperature and pressure.

As experiments are difficult to test on it, experts ${ }^{2,3}$ develop other approaches for calculation. The Duan group ${ }^{4-13}$ have done work of equation of state (EOS). They obtained the original EOS by integrating the virial equation. With the original and modified equations Duan et al., predicted the PVTx properties of geologic fluid over a broad area. The molecular dynamics simulation (MD) is employed to study this subject with the development of computer technology. Moller et al. ${ }^{14}$ investigated thermophysical properties of methane-ethane by molecular dynamics simulations. While Galliero et al. ${ }^{15}$ predicted dynamic viscosity of acid gas based on molecular dynamics with an empirical correlation which only density data is adjusted.

In this paper, we focus on using empirical correlations to predict dynamic viscosity and thermal conductivity of methane based on molecular dynamics simulations.

\section{MOLECULAR DYNAMICS SIMULATIONS}

Simulation details: Accurate intermolecular potential plays a pivotal role in the molecular simulation. For $\mathrm{CH}_{4}$, the present models ${ }^{13}$ have their unique benefits, respectively which all accord well with the experiments. With consideration of different models we choose the classical 12-6 Lennard-Jones $(\mathrm{LJ})^{16}$ potential, which is brief and widely utilized in molecular dynamics simulation of methane. And the description of Lennard-Jones potential is:

$$
\mathrm{U}_{\mathrm{LJ}}=4 \varepsilon_{\mathrm{CH}_{4}}\left[\left(\frac{\sigma_{\mathrm{CH}_{4}}}{\mathrm{r}_{\mathrm{ij}}}\right)^{12}-\left(\frac{\sigma_{\mathrm{CH}_{4}}}{r_{\mathrm{ij}}}\right)^{6}\right]
$$

where $U_{L J}$ is the potential energy, $r_{i j}$ is the distance between two interaction particles $\mathrm{i}$ and $\mathrm{j}, \sigma_{\mathrm{CH}_{4}}=3.3727 \times 10^{-10} \mathrm{~m}$ and $\varepsilon_{\mathrm{CH}_{4}}=1246.5 \mathrm{~J} / \mathrm{mol}$ are the adjustable parameters for the LJ potential. We only count the interaction within a cut off distance $1 \times 10^{-9} \mathrm{~m}$.

For the modeling system there are 512 methane molecules initial set uniform in a cube box which volume is $512 \times 10^{-27}$ $\mathrm{m}^{3}$. Technically, the original molecules number was 8000 . The difference is slight after several simulations tested with only particle number changed. We got 512 finalized $^{12}$. Parallelepiped periodic boundary condition is applied in $\mathrm{x}, \mathrm{y}, \mathrm{z}$ coordinate. Berendsen's ${ }^{17}$ method is employed to achieve isothermal- 
isobaric (NPT) ensemble. While particle trajectories are integral of leapfrog verlet ${ }^{18}$ algorithms. And process steps are 800000 within 10000 equilibration steps which time step is accepted as $5 \mathrm{fs}$.

We started the work at supercriticality with $10 \mathrm{MPa}$ each $10 \mathrm{~K}$ from $160-350 \mathrm{~K}$. Subsequently a more crucial region is tested which temperature is stable at $400 \mathrm{~K}$ while pressure changing from 110-140 MPa.

\section{RESULTS AND DISCUSSION}

Density: Among millions of thermophysical data that describe accurately of geologic fluid, we cite the results from National Institute of Standards and Technology (NIST), US (http://webbook.nist.gov/chemistry/fluid/) which produced REFPROP software.

It's convenient to obtain density from NPT ensemble. Fig. 1 is about comparison methane density at $10 \mathrm{MPa}$ between our simulation and experimental data from NIST. Our simulation results match well with the experimental data with average absolute deviation of $3.8 \%$ and a maximum deviation of $10 \%$ at $220 \mathrm{~K}$. The deviation is concentrate in the region between 190 and $240 \mathrm{~K}$ where the critical temperature located (Table-1). In this area our results slight above the NIST data since the particles clustered and act as liquid. From Fig. 2, the radial distribution function (RDF) of methane, it's shown that $220 \mathrm{~K}$ methane retain some indistinct character of liquid while at $160 \mathrm{~K}$ represent liquid and $350 \mathrm{~K}$ indicate gaseous. It should be noticed that we gain the density by molecular interactions which is differ from numerical analysis of equation of state. And this approach resembles experiments.

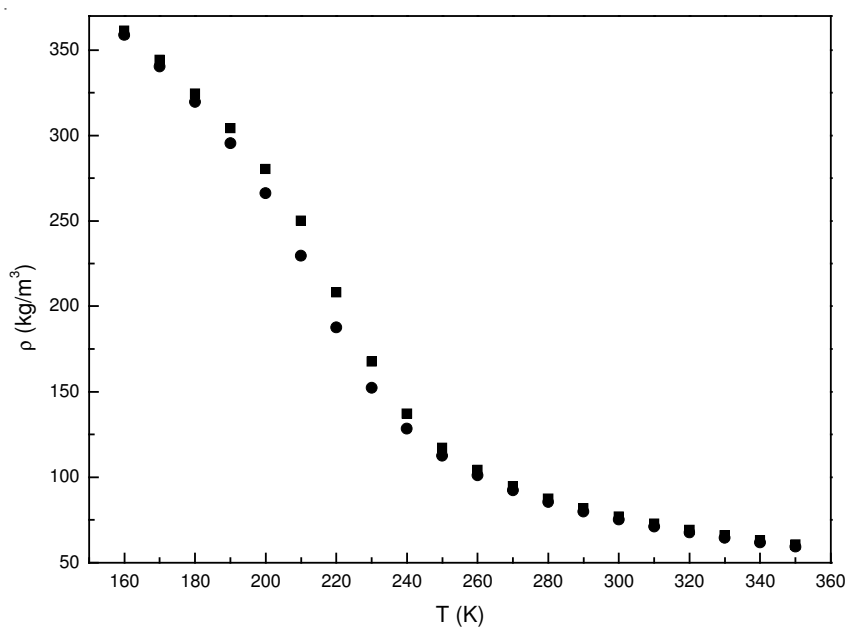

Fig. 1. Methane density $\left(\mathrm{kg} / \mathrm{m}^{3}\right)$ at $10 \mathrm{MPa}$ with temperature $(\mathrm{K}),(\mathbf{\square})$ our simulation results, $(\bullet)$ data of NIST

\begin{tabular}{cccc}
\multicolumn{4}{c}{ TABLE-1 } \\
& CRITICAL PROPERTIES OF METHANE \\
\hline $\begin{array}{c}\text { Critical } \\
\text { temperature } \\
(\mathrm{K})\end{array}$ & $\begin{array}{c}\text { Critical pressure } \\
(\mathrm{MPa})\end{array}$ & $\begin{array}{c}\text { Critical density } \\
\left(\mathrm{kg} / \mathrm{m}^{3}\right)\end{array}$ & $\begin{array}{c}\text { Critical } \\
\text { compressibility } \\
\text { factor }\end{array}$ \\
\hline 190.6 & 4.599 & 162.66 & 0.288 \\
\hline
\end{tabular}

Dynamic viscosity: As mentioned in introduction, we depend on an empirical correlation of Jossi et al. ${ }^{19}$ to predict

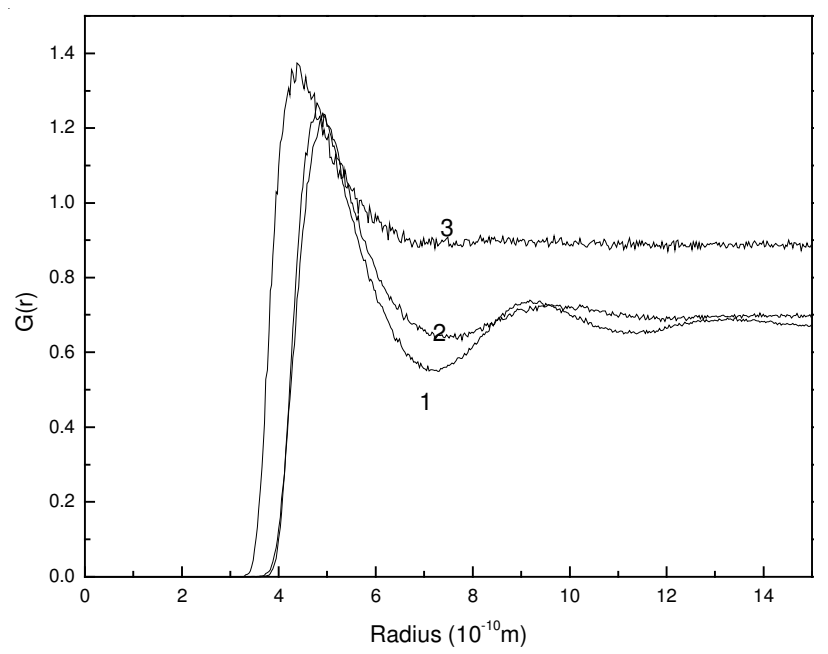

Fig. 2. Radial distribution function of methane at 1: $160 \mathrm{~K}, 2: 220 \mathrm{~K}$ and 3: $350 \mathrm{~K}$

dynamic viscosity of nonpolar methane. Since the work conditions are supercriticality, we select the equation which available at high pressure:

$$
\begin{aligned}
& {\left[\left(\eta-\eta^{\circ}\right) \xi+1\right]^{1 / 4}=} 1.023+0.23364 \rho_{\mathrm{r}}+0.58533 \rho_{\mathrm{r}}^{2} \\
&-0.40758 \rho_{\mathrm{r}}^{3}+0.093324 \rho_{\mathrm{r}}^{4} \\
& \eta^{\circ}= \frac{26.69(\mathrm{MT})^{0.5}}{\sigma^{2} \Omega_{\mathrm{V}}} \\
& \xi=\left(\frac{\mathrm{T}_{\mathrm{c}}}{\mathrm{M}^{3} \mathrm{p}_{\mathrm{c}}^{4}}\right)^{1 / 6}
\end{aligned}
$$

where $\eta$ is dynamic viscosity of high pressure, $\eta^{\circ}$ is dynamic viscosity of normal pressure calculate from eqn. $3, \rho_{\mathrm{r}}=\rho / \rho_{\mathrm{c}}$ is reduced density and $\xi$ is a parameter that depend on critical temperature and critical pressure eqn. 4 . And $\Omega_{\mathrm{V}}$ in eqn. 3 is the collision integral that estimate from correlation of Neufeld et al. ${ }^{20}$.

As is shown in Fig. 3, our results accord well with data of NIST which the average absolute deviation is $6.1 \%$ and the maximum deviation is $20 \%$ at $220 \mathrm{~K}$. It's no wonder that the deviation focus on the circumscription where we discussed at part of density. Further more, in the district when temperature over $250 \mathrm{~K}$, two groups data are perfect coincidence. This inspires us to extend the prediction in the more crucial region.

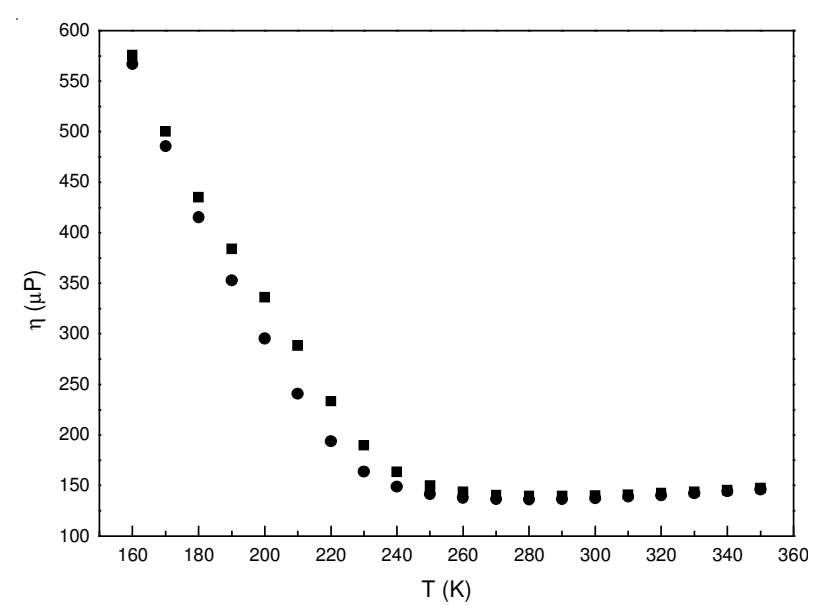

Fig. 3. Methane dynamic viscosity $(\mu \mathrm{P})$. ( $\square)$ our results, $(\bullet)$ data of NIST 
Thermal conductivity: Thermal conductivity is a coefficient which reflects the capability of heat transfer. The empirical correlation ${ }^{21}$ as follow:

$$
\begin{gathered}
\left(\lambda-\lambda^{\circ}\right) \Gamma Z_{\mathrm{c}}^{5}=1.14 \times 10^{-2}\left[\exp \left(0.67 \rho_{\mathrm{r}}\right)-1.069\right] \\
\lambda^{\circ}=-1.869 \times 10^{-3}+8.727 \times 10^{-5} \mathrm{~T}+1.179 \times 10^{-7} \mathrm{~T}^{2} \\
-3.614 \times 10^{-11} \mathrm{~T}^{3}
\end{gathered}
$$

where $\lambda$ is the thermal conductivity of high pressure, $\lambda^{\circ}$ is thermal conductivity of normal pressure, $\Gamma=210\left(\frac{\mathrm{T}_{\mathrm{c}} \mathrm{M}^{3}}{\mathrm{p}_{\mathrm{c}}^{4}}\right)^{1 / 6}$ is the reduced conductivity, $\mathrm{Z}_{\mathrm{c}}$ is the critical compressibility factor of methane.

It's predictable that maximum deviation is located around 220 K. From the statistics of results and Fig. 4, we confirm that the maximum deviation is $16.7 \%$ at $210 \mathrm{~K}$ while average absolute deviation is $5.2 \%$. It's interesting that deviation at lower temperature enlarge. We attribute it to the empirical correlation is more suit gaseous.

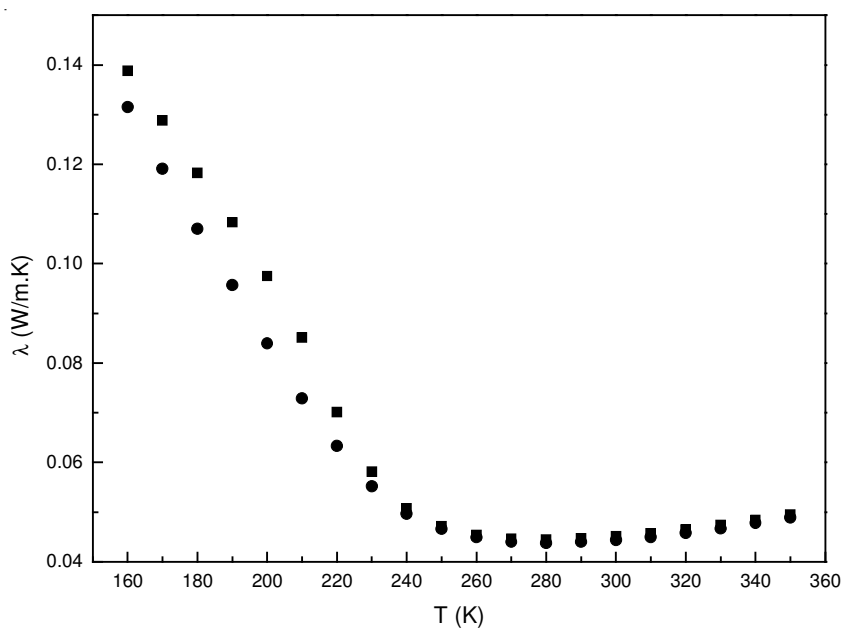

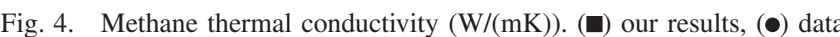
of NIST

Extension to more crucial region: It has come to light that methane reservoir under the earth's crust with supercritical state conditions. We simulated at $400 \mathrm{~K}$ while pressure changing from 1100-1400 atm (convert into standard unit is ca. 111-141 MPa) in succession.

Figs. 5-7 showed the results which we expanded the method to a higher pressure area. The density simulation seems perfect whereas the other two results deviated a bit larger. However, the statistical data showed the average absolute deviation of density is $0.23 \%$ while that of dynamic viscosity and thermal conductivity are 7.7 and $7.1 \%$, respectively. And the similar circumstance is existed in results of Galliero et al. ${ }^{22}$. It confirms that our simulation is correct while the eqns. 2 and 5 are not so appropriate for the supercritical state. We'd like to discuss this attractive issue in the future works.

\section{Conclusion}

The scheme proposed in this paper to predict methane thermophysical properties, more precisely dynamic viscosity

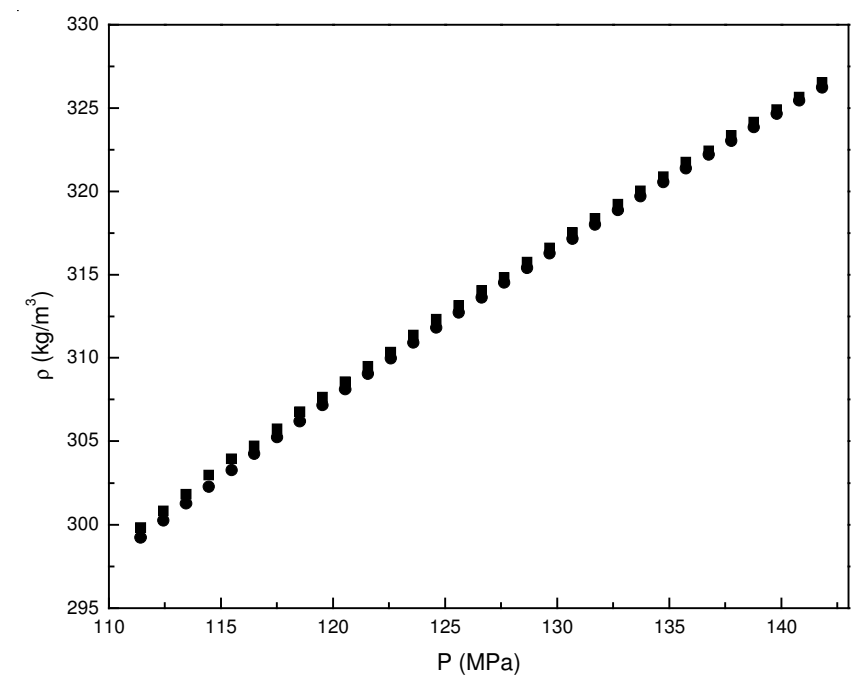

Fig. 5. Methane density $\left(\mathrm{kg} / \mathrm{m}^{3}\right)$ at $400 \mathrm{~K}$. (ロ) our simulation results, (•) data of (NIST)

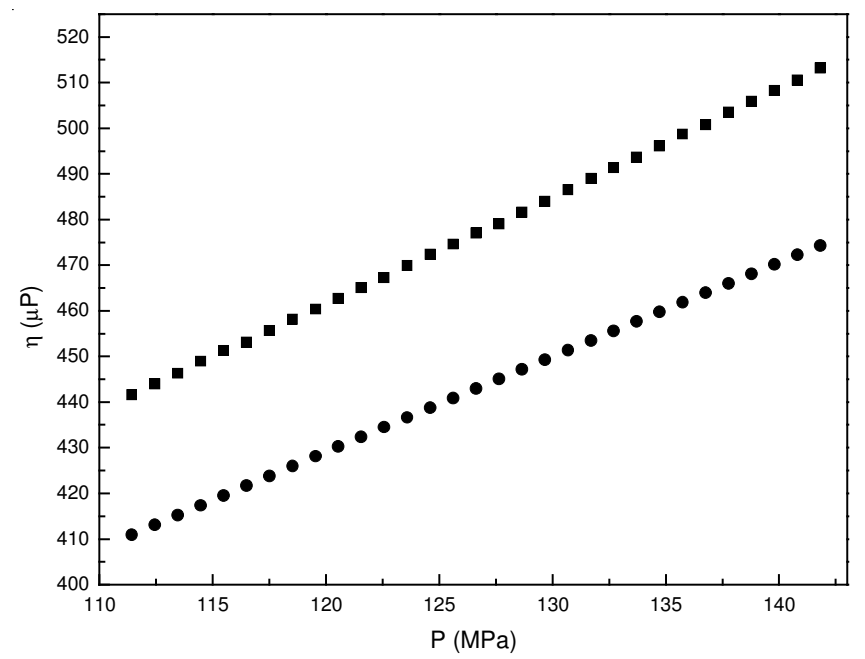

Fig. 6. Methane dynamic viscosity $(\mu \mathrm{P})$. ( $\square)$ our results, $(\bullet)$ data of NIST

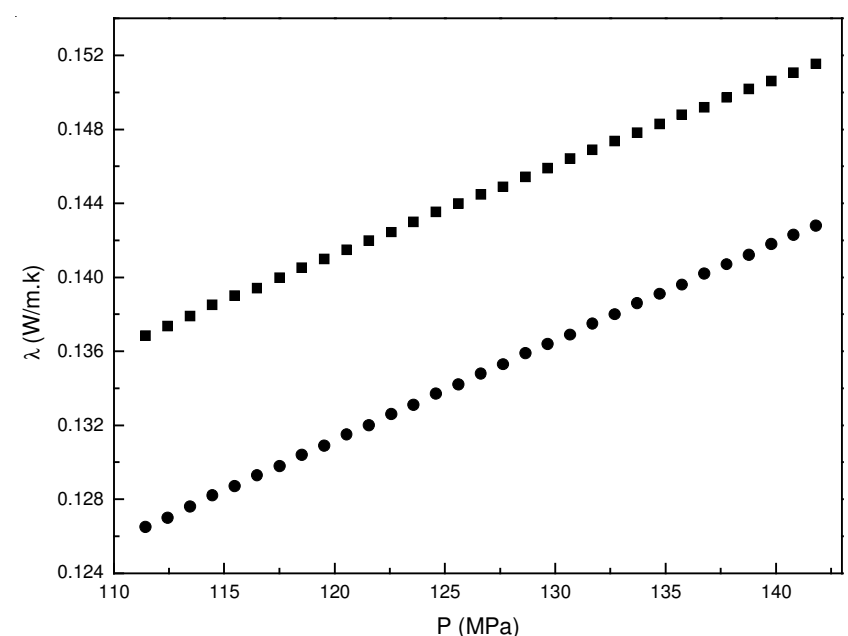

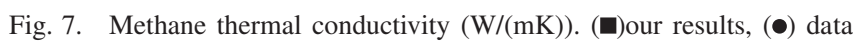
of NIST

and thermal conductivity, is based on molecular dynamics simulations with empirical correlations. It should be noticed that acquiring density access resembles experiments by molecular interactions which is differ from numerical analysis of 
equation of state. With this approach, we could calculate the methane thermophysical properties of supercriticality where the experiments are difficult to test on it. In our samples, the average absolute deviation is 3.8, 6.1 and 5.2 \% of density, dynamic viscosity and thermal conductivity, respectively at $10 \mathrm{MPa}$ with temperature changing from 160-350 K. Under the condition of supercritical state the density results matched perfect while simulated results of dynamic viscosity and thermal conductivity in average absolute deviation increased about $2 \%$. It confirms that our simulation is correct while empirical correlations are not so appropriate for the super-critical state.

\section{ACKNOWLEDGEMENTS}

This work was supported by National Natural Science Foundation of China (No. 50904050) and Open Fund (PLN1016) of State Key Laboratory of Oil and Gas Reservoir Geology and Exploitation (Southwest Petroleum University).

\section{REFERENCES}

1. E. Heidaryan, J. Moghadasi and A. Salarabadi, J. Nat. Gas Chem., 19, 552 (2010)

2 I. Tsivintzelis, G.M. Kontogeoris, M.L. Michelsen and E.H. Stenby, AIChE J., 56, 2965 (2010).

3 E.J. Rosenbaum, N.J. English, J.K. Johnson, D.W. Shaw and R.P. Warzinski, J. Chem. Phys. B, 111, 13194 (2007).

4 Z. Zhang and Z. Duan, Geochim. Cosmochim. Acta, 66, 3431 (2002).
5 Z. Duan and S. Mao, Geochim. Cosmochim. Acta, 70, 3369 (2006).

6 Z. Duan, N. Moller and J.H. Weare, Geochim. Cosmochim. Acta, 64, 1069 (2000).

7 Z. Duan, N. Moller and J.H. Weare, Geochim. Cosmochim. Acta, 60, 1209 (1996).

8 Z. Duan, N. Moller, J. Greenberg and J.H. Weare, Geochim. Cosmochim. Acta, 56, 1451 (1992).

9 Z. Duan, N. Moller and J.H. Weare, Geochim. Cosmochim. Acta, 56, 3839 (1992).

10 Z. Duan, N. Moller and J.H. Weare, Geochim. Cosmochim. Acta, 56, 2605 (1992).

11 Z. Duan, N. Moller and J.H. Weare, Geochim. Cosmochim. Acta, 56, 2619 (1992).

12 Z.H. Duan, Sci. China Earth Sci., 40, 393 (2010).

13 C. Zhang, Z. Duan and Z. Zhang, Geochim. Cosmochim. Acta, 71, 2036 (2007).

14 D. Moller, J. Oprzynski, A. Muller and J. Fischer, Mol. Phys., 75, 363 (1992).

15 G. Galliero, C. Boned and A. Baylaucq, Ind. Eng. Chem. Res., 44, 6963 (2005).

16 G. Galliero, C. Nieto-Draghi, C. Boned, J. B. Avalos, A.D. Mackie, A. Baylaucq and F. Montel, Ind. Eng. Chem. Res., 46, 5238 (2007).

17 H.J.C. Berendsen, J.P.M. Postma, W.F. van Gunsteren, A. DiNola and J.R. Haak, J. Chem. Phys., 81, 3684 (1984).

18 R.J. Sadus, Molecular Simulation of Fluids: Theory, Algorithms and Object-Orientation, Elsevier, Amsterdam, pp. 226-228 (1999).

19 J.A. Jossi, L.I. Stiel and G. Thodos, AIChE J., 8, 59 (1962).

20 P.D. Neufeld, A.R. Janzen and R.A. Aziz, J. Chem. Phys., 57, 1100 (1972).

21 L.I. Stiel and G. Thodos, AIChE J., 10, 26 (1964).

22 G. Galliero and C. Boned, Fluid Phase Equilib., 269, 19 (2008). 